\title{
A modified method for isolation of bladder cancer stem cells from a MB49 murine cell line
}

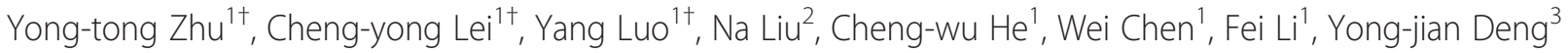 \\ and Wan-long Tan ${ }^{1 *}$
}

\begin{abstract}
Background: The vaccine was efficiently effective against bladder cancer in earlier studies. However, a part of the mouse bladder tumour regrew due to regression after a period of time as the cancer stem cells could not be eliminated. In this study, we showed a modified method for the isolation of MB49 bladder cancer stem cells (MCSCs).
\end{abstract}

Methods: Through a comparison of different serum-free culture mediums (SFM), MCSCS were isolated by a combination of the limited dilution method and the optimal SFM method. The characterizations of MCSCs were verified by the fluorescence activated cell sorting, the quantitative polymerase chain reaction, the western blotting, the cell proliferation assay, the soft agar assay, the transwell assay, the resistance to chemotherapy assay and the tumor xenograft formation assay.

Results: The optimal SFM contained a RPMI1640+ epidermal growth factor (20 ng/ml), a basic fibroblast growth factor $(20 \mathrm{ng} / \mathrm{ml})$, a leukemia inhibitory factor $(20 \mathrm{ng} / \mathrm{ml})$, a B-27 serum-free supplement $(20 \mu \mathrm{l} / \mathrm{ml})$, and a bovine serum albumin $(4 \mu \mathrm{g} / \mathrm{ml})$. MCSCs possessed the high expression of cancer stem cell markers (CD133, CD44, OCT4, NANOG, and ABCG2) and the ability of differentiation. In functional comparisons, MCSCs had higher proliferative abilities, lower susceptibility to chemotherapy, greater migration in vitro, and stronger tumorigenic abilities in vivo.

Conclusion: MCSCs displayed specific cancer stem cells properties. Our study showed MCSCs were isolated successfully with a modified method using a combination of limited dilution and SFM methods.

Keywords: Bladder cancer, MB49 cell line, Cancer stem cells, Proliferation, Chemotherapy

\section{Background}

The MB49 bladder cancer cell vaccine induced a specific antitumor immunity and was efficiently effective against metastatic bladder cancer in our earlier studies [1-3]. However, we also found that a part of the mouse bladder tumor regrew after experiencing regression for a period of time because the cancer stem cells (CSCs), or cancer-initiating cells, could not be eliminated. Recent findings supported the notion that relapses of solid tumors may be attributed to the inability of traditional chemotherapies and radiotherapies to eradicate CSCs [4]. Our former bladder cancer vaccine was not the CSC

\footnotetext{
* Correspondence: tanwanlong@gmail.com

'Equal contributors

'Department of Urology, Nanfang Hospital, Southern Medical University, Guangzhou, Guangdong 510515, P.R. China

Full list of author information is available at the end of the article
}

vaccine, which was unable to induce specific immunities responsible for CSCs.

Limited dilution assays were first used to establish $\mathrm{CD}_{133^{+}}$single cell-derived progenies of colorectal cancer in 2010 [5]. The serum-free culture medium (SFM) method had been used to isolate CSCs from tumors, but it was limited due to the lack of purity in the CSCs [6]. As we known, the combination of the limited dilution method and SFM method has not been used to isolate the CSCs, which could improve the purity of cell sorting. Cancer stem cells from a MB49 bladder cancer cell line (MCSCs) had not been demonstrated before, and the isolation of MCSCs would provide a model for the development of bladder cancer vaccine research. We provide a modified method here by 
combining the limited dilution and SFM methods to isolate MCSCs.

\section{Methods}

\section{Optimal SFM for MCSCs}

The mediums reported previously to support the expansion of CSCs were different $[7,8]$. Furthermore, the defined SFM formulations reported in previous literature have not been able to support the MCSCs. Based on these considerations, a sequential approach was taken to identify defined SFMs for the successful isolation and expansion of MCSCs.

The culture media and recombinant growth factors tested are shown in Table 1. The epidermal growth factor (EGF), fibroblast growth factor basic (FGF-b), leukemia inhibitory factor (LIF), and the B-27 serum-free supplement (B27) have previously supported the expansion of different kinds of CSCs $[9,10]$. The most important serum substitute is bovine serum albumin (BSA), and the optimized concentration of BSA is $0.4 \%$ [11]. The different combinations shown in Table 2, e.g. No. 5 are $\mathrm{EGF}+\mathrm{B} 27+\mathrm{BSA}+\mathrm{RPMI} 1640$.

\section{Cell culture for the MB49 cell line}

The murine bladder cancer cell line, MB49, was a gift from Dr. I. C. Summerhayes from the Lahey Clinic in Burlington, Massachusetts [1-3]. MB49 cells were cultured in RPMI1640 that contained 10\% fetal bovine serum (FBS, Thermo Scientific HyClone, Logan, Utah) at $37^{\circ} \mathrm{C}$ in a $5 \% \mathrm{CO}_{2}$ humidified incubator.

\section{Comparison of culture medium and supplements}

The accutase-enzyme cell detachment medium (Accutase, eBioscience, San Diego, California) was used for digestion. Then the different culture mediums were added to dilute the Accutase in order to stop digestion. Finally, the MB49 cells were dissociated into the single cell suspension and seeded at a density of $2 \times 10^{3}$ cells per well as shown in Table 2. There were various culture mediums in 96-well plates with ultra low attachment surface (Corning Life Sciences, Union City, California). Cells were incubated for a subsequent 5 days. Then $10 \mu \mathrm{l}$ of the Cell Counting Kit-8 reagent (CCK-8, Dojindo Molecular Technologies,

Table 1 Cell culture medium and supplements

\begin{tabular}{lll}
\hline Reagent & \multicolumn{1}{c}{ Suppliers } & Concentration \\
\hline EGF & Peprotech, Rocky Hill, NJ, USA & $20 \mathrm{ng} / \mathrm{ml}$ \\
FGF-b & Peprotech & $20 \mathrm{ng} / \mathrm{ml}$ \\
LIF & eBioscience, San Diego, CA, USA & $20 \mathrm{ng} / \mathrm{ml}$ \\
B27 & Invitrogen, Grand Island, NY, USA & $20 \mu \mathrm{l} / \mathrm{ml}$ \\
BSA & Thermo Scientific HyClone, Logan, UT, USA & $4 \mathrm{mg} / \mathrm{ml}$ \\
RPMI1640 & Thermo Scientific HyClone & $1 \times$ \\
DMEM/F12 & Thermo Scientific HyClone & $1 \times$ \\
\hline
\end{tabular}

Table 2 Combination of medium and supplements

\begin{tabular}{|c|c|c|c|c|c|c|c|c|c|c|c|c|c|c|c|c|c|}
\hline No. & 1 & 2 & 3 & 4 & 5 & 6 & 7 & 8 & 9 & 10 & 11 & 1 & & 13 & 14 & 15 & 16 \\
\hline EGF & & & $\sqrt{ }$ & & $\sqrt{ }$ & & & $\sqrt{ }$ & $\sqrt{ }$ & & $\sqrt{ }$ & & & $\sqrt{ }$ & $\sqrt{ }$ & $\sqrt{ }$ & $\sqrt{ }$ \\
\hline FGF-b & & & & $\sqrt{ }$ & & & & & & $\sqrt{ }$ & $\sqrt{ }$ & $v$ & & & $\sqrt{ }$ & $\sqrt{ }$ & $\sqrt{ }$ \\
\hline LIF & & $\sqrt{ }$ & & & & & & $\sqrt{ }$ & & & $\sqrt{ }$ & $\sqrt{ }$ & & $\sqrt{ }$ & & $\sqrt{ }$ & $\sqrt{ }$ \\
\hline B27 & $\sqrt{ }$ & & & & $\sqrt{ }$ & & & & & $\sqrt{ }$ & & v & & $\sqrt{ }$ & $\sqrt{ }$ & $\sqrt{ }$ & $\sqrt{ }$ \\
\hline BSA & $\sqrt{ }$ & & $\sqrt{ }$ & $\sqrt{ }$ & & & & $\sqrt{ }$ & $v$ & $\sqrt{ }$ & $\sqrt{ }$ & $\sqrt{ }$ & & $\sqrt{ }$ & $\sqrt{ }$ & $\sqrt{ }$ & $\sqrt{ }$ \\
\hline RPMI 1640 & $\sqrt{ }$ & & $\sqrt{ }$ & $\sqrt{ }$ & & & & $\sqrt{ }$ & & $\sqrt{ }$ & $\sqrt{ }$ & v & & $\sqrt{ }$ & $\sqrt{ }$ & & $\sqrt{ }$ \\
\hline DMEM/F12 & & & & & & & & & & & & & & & & $\sqrt{ }$ & \\
\hline
\end{tabular}

Kumamoto, Japan) were added at a fixed time in 1, 2, 3, 4, and 5 days. After a 4 hour incubation, the absorbance value was measured at $450 \mathrm{~nm}$ using an EnSpire 2300 multilabel reader (PerkinElmer, Singapore).

After 7 days, the colonies with a diameter greater than $50 \mu \mathrm{m}$ were counted with an inverted microscope (Nikon, Japan), and the cell morphologies in various culture mediums were recorded with a camera (Nikon, Japan).

\section{Establishment of MCSCs Limited dilution method}

The MB49 cells were digested with Accutase. They were then counted and diluted tenfold at a limited 3-4 times to form a density of 5 cells per milliliter in an optimal SFM with plated $200 \mu \mathrm{L}$ in a 96-well plate. Finally, single cells were marked and observed every day.

\section{Passage culture}

The Passage 1 single cells were cultured in the optimal SFM, and we removed the supernatant and supplemented fresh SFM every 5-7 days. By the 30th day, the single cells had grown to single-cell spheres so large that they were visible. They were digested with Accutase, dispersed mechanically, and plated in a 24-well plate with an ultra low attachment surface (Corning Life Sciences) before forming passage 2 cells.

Table 3 Primers of selected genes

\begin{tabular}{clc}
\hline Gene name & \multicolumn{1}{c}{ Primers (forward/reverse) } & $\begin{array}{r}\text { Base pairs } \\
\text { of product }\end{array}$ \\
\hline CD133 & F: 5'-CGGGATCCGAAAAACTGATCTGT-3' & $615 \mathrm{bp}$ \\
& R: 5'-CCGCTCGAGTTACCTAGTTACTCTCTCC-3' & \\
CD44 & F: 5'-CCCTGCTACCAGAGACCAAGAC-3' & $401 \mathrm{bp}$ \\
& R; 5'-GCAGGTCCTTGTCTCATCAGC-3' & \\
NANOG & F: 5'-CAGCTGTGTGTACTCAATGATAGATTT-3' & $179 \mathrm{bp}$ \\
& R: 5'-ACACCATTGCTATTCTTCGGCAGTTG-3' & \\
OCT4 & F: 5'-TCAGCCAAACGACCATCTGC-3' & $205 \mathrm{bp}$ \\
& R: 5'TTCTCCAGGTGCCTCTCAC-3' & \\
GAPDH & F: 5'-CCATGGAGAAGGCTGGGG-3' & $198 \mathrm{bp}$ \\
& R: 5'-CAAAGTTGCATCCATGACC-3' & \\
\hline
\end{tabular}


Table 4 Concentrations of chemotherapeutic agents

\begin{tabular}{ccccc}
\hline Agents & \multicolumn{4}{c}{ Concentrations } \\
\hline Paclitaxel & $10 \mathrm{nM}$ & $100 \mathrm{nM}$ & $1 \mu \mathrm{M}$ & $10 \mu \mathrm{M}$ \\
Doxorubicin & $10 \mathrm{nM}$ & $100 \mathrm{nM}$ & $1 \mu \mathrm{M}$ & $10 \mu \mathrm{M}$ \\
Cisplatin & $5 \mu \mathrm{M}$ & $10 \mu \mathrm{M}$ & $15 \mu \mathrm{M}$ & $20 \mu \mathrm{M}$ \\
Mitomycin & $10 \mu \mathrm{M}$ & $80 \mu \mathrm{M}$ & $640 \mu \mathrm{M}$ & $5.12 \mathrm{mM}$ \\
\hline
\end{tabular}

The Passage 2 cells were cultured with freshly changed SFM every 3-4 days. By the 15th day, most of the cells had grown to spheres large enough to view. Then the spheres were collected, centrifuged for 5 minutes at $800 \mathrm{rpm}$, digested with Accutase, dispersed mechanically, and plated in a 6-well plate with an ultra low attachment surface (Corning Life Sciences) before forming passage 3 cells. The cells had expanded to a T25 culture flask (Corning Life Sciences) through multiple passages using the same protocol.

\section{Characterizations of MCSCs}

Expression of MCSCs markers

Fluorescence activated cell sorting (FACS) The MB49 cells and MCSCs were harvested respectively. They were dissociated at a density of $1 \times 10^{4}$ cells in a $100 \mu \mathrm{l}$ autoMACS running buffer (Miltenyi Biotec, Bergisch Gladbach, Germany), labeled with $20 \mu \mathrm{l}$ PE mouse anti-prominin-1 (Miltenyi Biotec) and FITC mouse antiCD44 (Miltenyi Biotec), incubated for 20 minutes at $4^{\circ} \mathrm{C}$, and washed twice with phosphate buffered saline (PBS). To set the background fluorescence levels, we used the PE rat IgG1 $\kappa$ isotype control (eBioscience) and the TITC rat IgG2b $\kappa$ isotype control (eBioscience) as the negative control. The ratio of $\mathrm{CD} 44^{+} \mathrm{CD} 133^{+}$cells was evaluated using a BD FACSAria cell sorter (Becton-Dickinson, San Jose, California).

Quantitative polymerase chain reaction (qPCR) The total RNAs extracted were isolated by using the Arcturus PicoPure RNA isolation kit (Applied Biosciences, Carlsbad, New Mexico). The RNA quality was verified by the Bioanalyzer RNA Pico Chip (Agilent Technologies, Santa Clara, California). The two micrograms of total RNA were reverse transcribed with Superscript III (Invitrogen, Grand Island, New York) to synthesize the first-strand cDNA. The cDNA was amplified with SYBR green PCR master mix (Bio-Rad, Hercules, California) on a 7500 real time PCR system (AB Applied Biosystems, Singapore). The cycling conditions were $95^{\circ} \mathrm{C}$ for $10 \mathrm{~s}$ (denaturation) and $60^{\circ} \mathrm{C}$ for $60 \mathrm{~s}$ (annealing and extension). The primer sequences are listed in Table 3. Normalization and fold changes were calculated using the $\Delta \Delta C_{t}$ method [12]. The gene expression of GAPDH was used as a negative control.
Western blotting (WB) Equal amounts of the protein samples extracted were separated with $10 \%$ sodiumdodecyl sulfate -polyacrylamide gel and transferred to polyvinylidene difluoride membranes (Millipore, Billerica, Massachusetts) electrophoretically. Filters were blocked in the PBS with 5\% skim milk and incubated overnight at $4{ }^{\circ} \mathrm{C}$ with the primary antibody anti-OCT4 (Abcam, Cambridge, Massachusetts), anti-NANOG (Abcam), antiABCG2 (Abcam), and anti- $\beta$-actin antibody (Abcam). The filters were then incubated with conjugated anti-mouse secondary antibodies (Abcam)[13]. The protein bands were detected by Fluor Chem FC2 (Alpha Innotech, San Leandro, California) and analyzed by Image Lab software.

\section{Differentiation}

The MCSCs were collected, dissociated into single cells, and cultured in RPMI1640 supplemented with 10\% FBS to induce cell differentiation. Meanwhile, the MCSC spheres were cultured by the same method.

\section{Functional comparison}

Cell proliferation assay The cells were plated at a number of $1 \times 10^{3}$ in a 96-well plate and incubated for $1,2,3$, 4,5 , and 6 days respectively. We then added $10 \mu \mathrm{l}$ CCK-8, the samples were incubated for 4 hours, and the absorbance values were measured as before.

Soft agar assay The cells were resuspended at a density of $1 \times 10^{4} / \mathrm{ml}$ with a bottom of $0.66 \%$ agar (Beyotime, Jiangsu, China) while the medium was supplemented with $10 \%$ FBS and layered on the top was a $1.32 \%$ agar supplemented with $20 \%$ FBS on 6-well plates respectively [13]. The plates were incubated for three weeks, and then the colonies with diameters greater than $50 \mu \mathrm{m}$ were counted.

Migration abilities in vitro The cells were seeded at a number of $1 \times 10^{4}$ in $0.25 \mathrm{ml}$ of pure RPMI1640 on a $6.5-\mathrm{mm}$ pore-size polycarbonate membrane chamber inserted in a transwell apparatus (Costar, Cambridge, Massachusetts). $0.75 \mathrm{ml}$ of the RPMI1640 medium that contained 10\% FBS was added to the lower chamber. Then the cells were incubated for 24 hours. The cells that had migrated to the bottom surface of the insert were fixed in paraformaldehyde for 20 minutes, stained in giemsa for 15 minutes, rinsed in PBS, and inspected via inverted microscopy.

Resistance to chemotherapy abilities The cells were seeded at a number of $1 \times 10^{4}$ in a 96-well plate. After 24 hours, the chemotherapeutic agents mitomycin (Sigma-Aldrich, St. Louis, Missouri), cisplatin (Sigma-Aldrich), paclitaxel (Sigma-Aldrich), and doxorubicin (Sigma-Aldrich) 


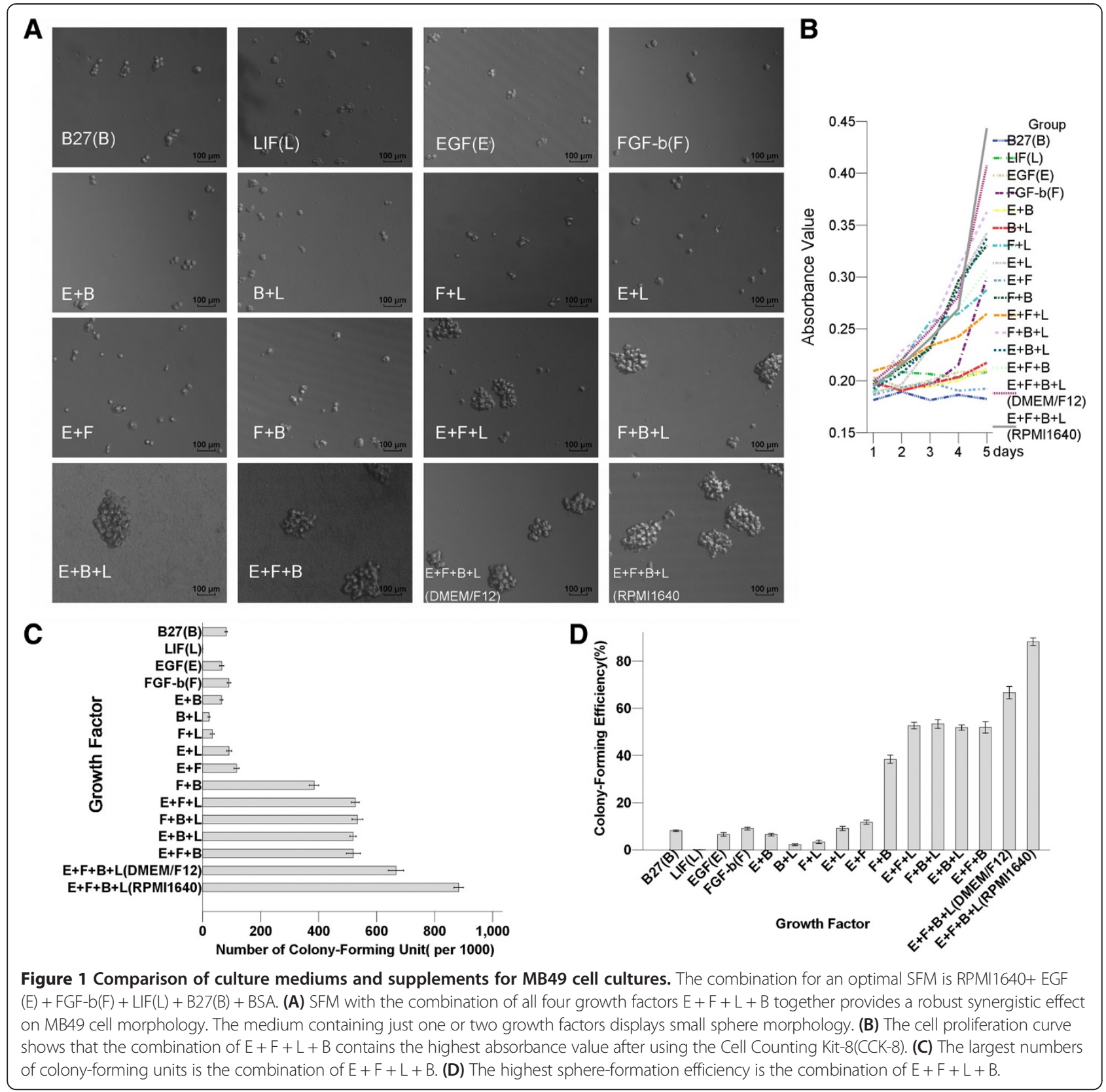

were added with different concentrations (Table 4). The cells were treated for a subsequent 96 hours. Therefore, $10 \mu \mathrm{l}$ of CCK- 8 were added to each well, and after 4 hours of incubation, the absorbance values were measured. The cell viability that corresponded to each drug treatment was expressed as the percentage of absorbance values of the treated wells related to the untreated control wells [12].

Tumorigenic abilities in vivo All of the experimental procedures with animals used in the present study have been given prior approval by the Ethics Committee of Southern Medical University under Contract 2011016. 4-week-old immune deficient nude mice (Center of Experimental Animals, Southern Medical University, Guangzhou, China) were maintained and treated under specific, pathogen-free conditions. The cells were injected with gradient concentration subcutaneously into the nude mice, at a number from $1 \times 10^{2}$ to $1 \times 10^{4}$ in MCSCs and from $1 \times 10^{4}$ to $1 \times 10^{6}$ in MB49 cells. The tumor xenograft formation was observed every week. At the end of eight weeks, the mice were sacrificed by cervical dislocation, the tumor engrafts were removed, and the volume of tumors was measured by using the formula $d^{2} \times D / 2$, where $d$ and $D$ were the shortest and the longest diameters respectively [14]. 


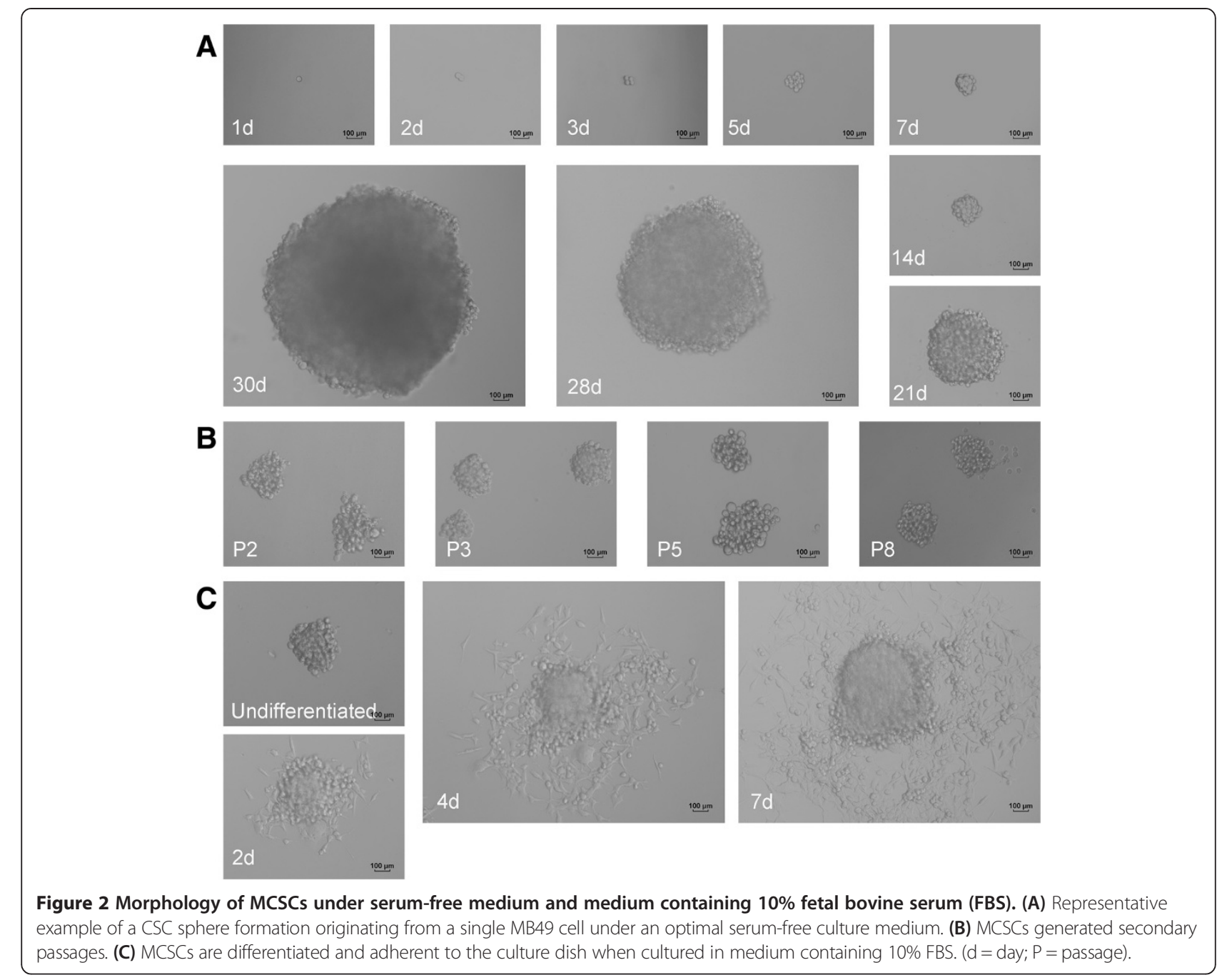

\section{Statistical analysis}

SPSS19.0 software was used for the statistical evaluations. All of the data was expressed as the mean \pm standard deviation and analyzed using one-way ANOVA. $\mathrm{P}<0.05$ was considered statistically significant.

\section{Results}

\section{Comparison of culture medium and supplements for MB49 cell culture}

The SFM with the combination of all four growth factors (EGF, FGF-b, LIF, and B27) together provided a robust synergistic effect on cell proliferation. The medium contained just one or two growth factors and displayed small sphere morphology (Figure 1a). The cell proliferation curve showed that the combination of EGF, FGF-b, LIF, and B27 contained the highest absorbance value using CCK-8 (Figure 1b). The numbers of colony-forming units and colony-forming efficiencies showed the same trend (Figure 1cd). The cells grown in DMEM/F12 displayed a similar colony-forming potential compared to those grown in RPMI1640. The combination of the optimal SFM was RPMI1640 + EGF $(20 \mathrm{ng} / \mathrm{ml})+\mathrm{FGF}-\mathrm{b}(20 \mathrm{ng} / \mathrm{ml})+\mathrm{LIF}$ $(20 \mathrm{ng} / \mathrm{ml})+\mathrm{B} 27(20 \mu \mathrm{l} / \mathrm{ml})+\mathrm{BSA}(4 \mu \mathrm{g} / \mathrm{ml})$.

\section{Establishment of MCSCs in SFM}

The limited dilution method showed that only a 2-3 percentage of MB49 cells generated CSC spheres in SFM. The passage 1 single MB49 cell formed a CSC sphere within 30 days in optimal SFM. The MCSCs were passaged after 15 days to form new tumor spheres, and most MCSCs generated secondary spheres. (Figure 2ab).

\section{Characterizations of MCSCs Expression of CSCs markers}

As demonstrated by the FACS analysis, the fraction of CD44 ${ }^{+}$cells in MB49 cells was higher than that of MCSCs. However, the fraction of $\mathrm{CD} 133^{+} \mathrm{CD} 44^{+}$cells was $19.83 \pm 0.68 \%$ in MCSCs and $3.57 \pm 0.38 \%$ in MB49 cells, which was elevated in MCSCs relative to MB49 cells $(\mathrm{P}<0.05$, Figure $3 \mathrm{a})$. 


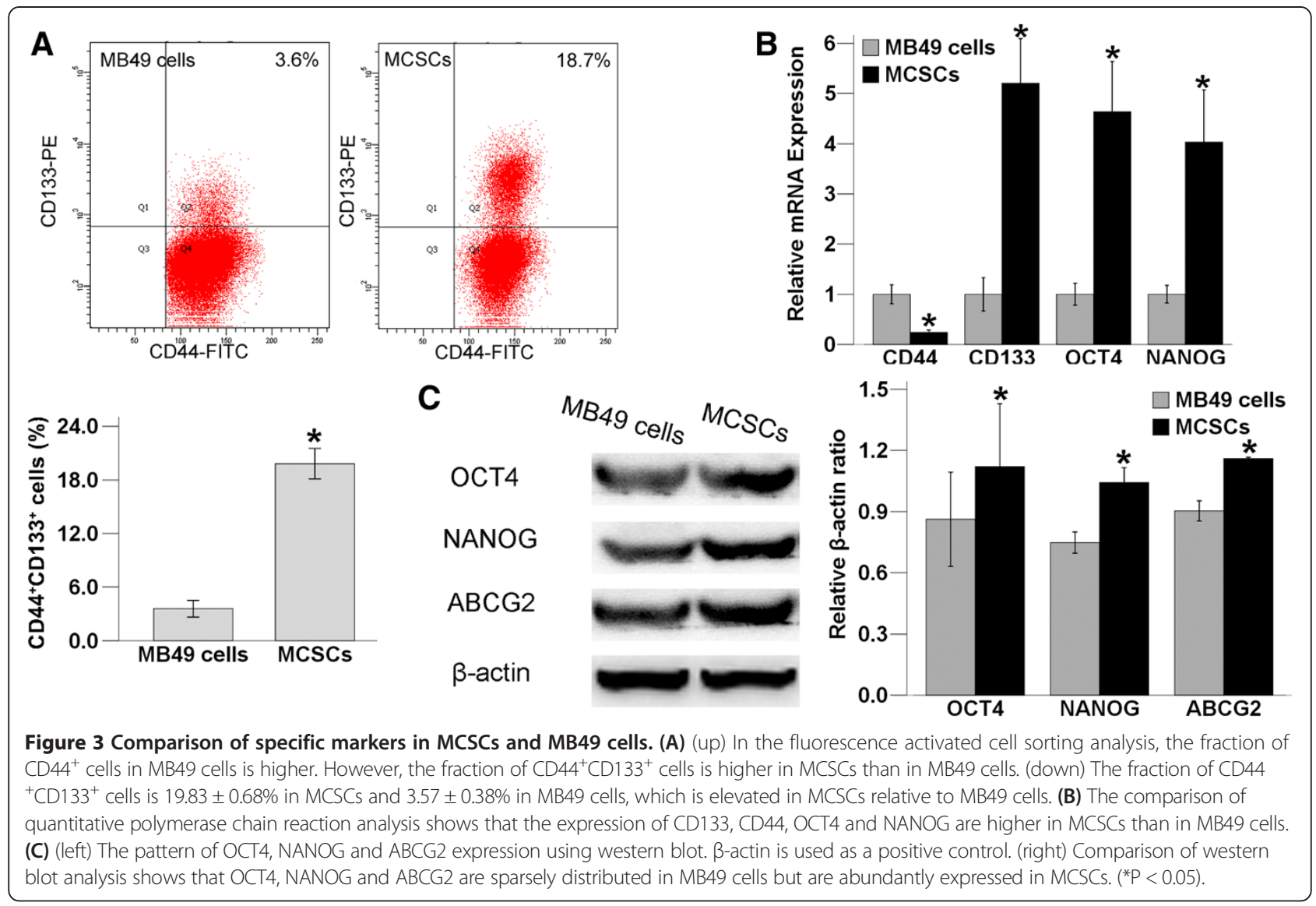

The relative levels of CD133, OCT4 and NANOG were higher in MCSCs using the qPCR experiment, being 5 times as high as observed in MB49 cells. However, the level of CD44 was higher in MB49 cells $(\mathrm{P}<0.05$, Figure $3 \mathrm{~b})$.

OCT4, NANOG and ABCG2 were both expressed in MCSCs and in MB49 cells by the WB assay. They were sparsely distributed in MB49 cells, but they were abundantly expressed in MCSCs $(\mathrm{P}<0.05$, Figure $3 \mathrm{c})$.

\section{Differentiation}

MCSCs were globular and floating in SFM. When the MCSCs were reseeded with a medium containing $10 \%$ FBS, they became flat after being differentiated and attached to the culture dish (Figure 2c).

\section{Functional comparison}

MCSCs increased the proliferation as compared with MB49 cells in the SFM on day 4, 5, 6 after using CCK-8 in the cell proliferation assay $(\mathrm{P}<0.05$; Figure $4 \mathrm{a})$. The soft agar assay revealed that MCSCs formed bigger and more numerous colonies than MB49 cells did $(\mathrm{P}<0.05$; Figure $4 \mathrm{~b})$. Both assays showed that MCSCs possessed highly proliferative abilities.
Under the same incubation conditions, the number of invaded MCSCs were more than that of MB49 cells $(\mathrm{P}<0.05$; Figure $4 \mathrm{c})$. Transwell migration assays displayed that MCSCs contained higher transmembrane activity than MB49 cells.

Compared to MB49 cells, MCSCs showed higher cell viabilities after being treated with different concentrations of mitomycin, cisplatin, paclitaxel, and doxorubicin in Figure 4d. MCSCs demonstrated lower susceptibility to all these traditional anticancer agents.

MCSCs caused a more remarkable tumor volume than MB49 cells did. Immune deficient nude mice injected with $1 \times 10^{6}$ in MB49 cells or $1 \times 10^{3}$ in MCSCs formed xenografts, those injected with $1 \times 10^{5}$ in MB49 cells or $1 \times 10^{2}$ in MCSCs did not. The morphology of H\&E stained xenograft tumor sections from MCSCs resembled tumor tissue from MB49 cells (Figure 4e). Xenograft formation showed that MCSCs possessed strongly tumorigenic ability in vivo.

\section{Discussion and conclusions}

To facilitate the transition of MCSCs to vaccine applications, advances in expanding MCSCs had become an absolute necessity. There were three methods that have been used to isolate CSCs from tumors: specific cell surface markers, SFM, and side population cells. These methods 


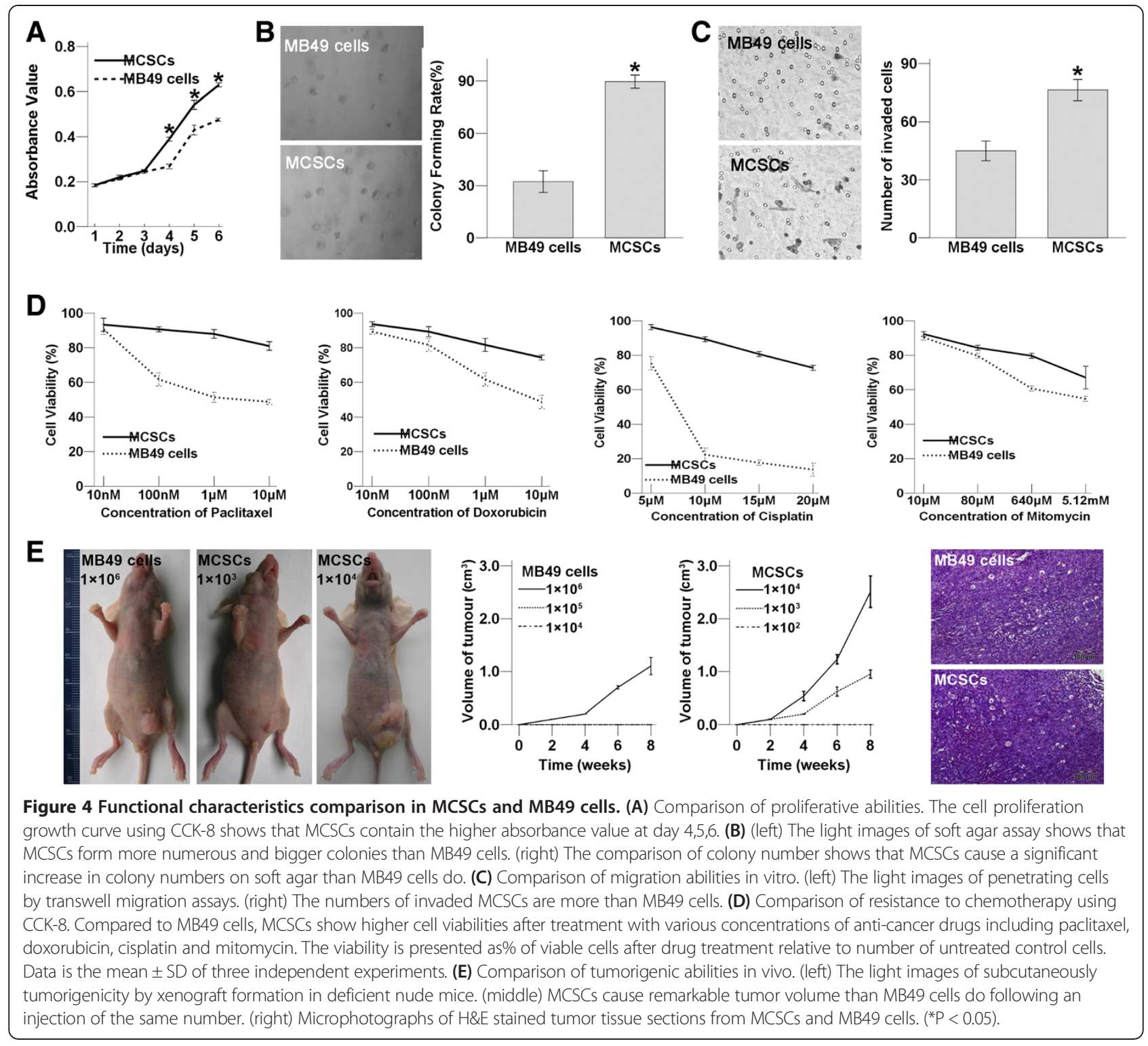

were limited due to the lack of purity of CSCs or the purity was not enough for CSCs [6]. Limited dilution assay was mostly used to assess the tumorigenic activity of xenograft cells [15]. However, the limited dilution method in our study was different, which allowed MCSCs sphere formation to originate from a single cell before improving the purity of CSCs (Figure 5). The limited dilution method showed that only a small percentage of MB49 cells generated CSC spheres, and the proportion was similar to other scholars' results [16].

Considering that the serum caused irreversible differentiation of stem cells, SFM selection might be useful for CSCs expansion and would allow for maintenance of an undifferentiated stem cell status [17]. Accutase, which is one kind of digested enzyme, was different from trypsin and did not need serum to stop digestion.
Accutase stopped digestion by adding 50 times as much SFM to dilute the enzyme, so MCSCs could maintain an undifferentiated status.

Due to the heterogeneity of different cancers, the optimal medium for the growth of CSCs may vary from case to case. A supplement medium that is critical to one line may be of no benefit or even adverse to the other. Therefore, it is recommended to perform experiments by choosing the optimal supplement composition for the MB49 cell line. Our study suggests that the medium should contain four stimulated factors: LIF, B27, EGF and FGF-b, which would together provide an optimal sphere formation with the MCSCs having survived continuous passage in culture. In contrast, MB49 cells do not proliferate and expire under SFM during serial passages. To our knowledge, this is the first report about the isolation and expansion of MCSCs via 


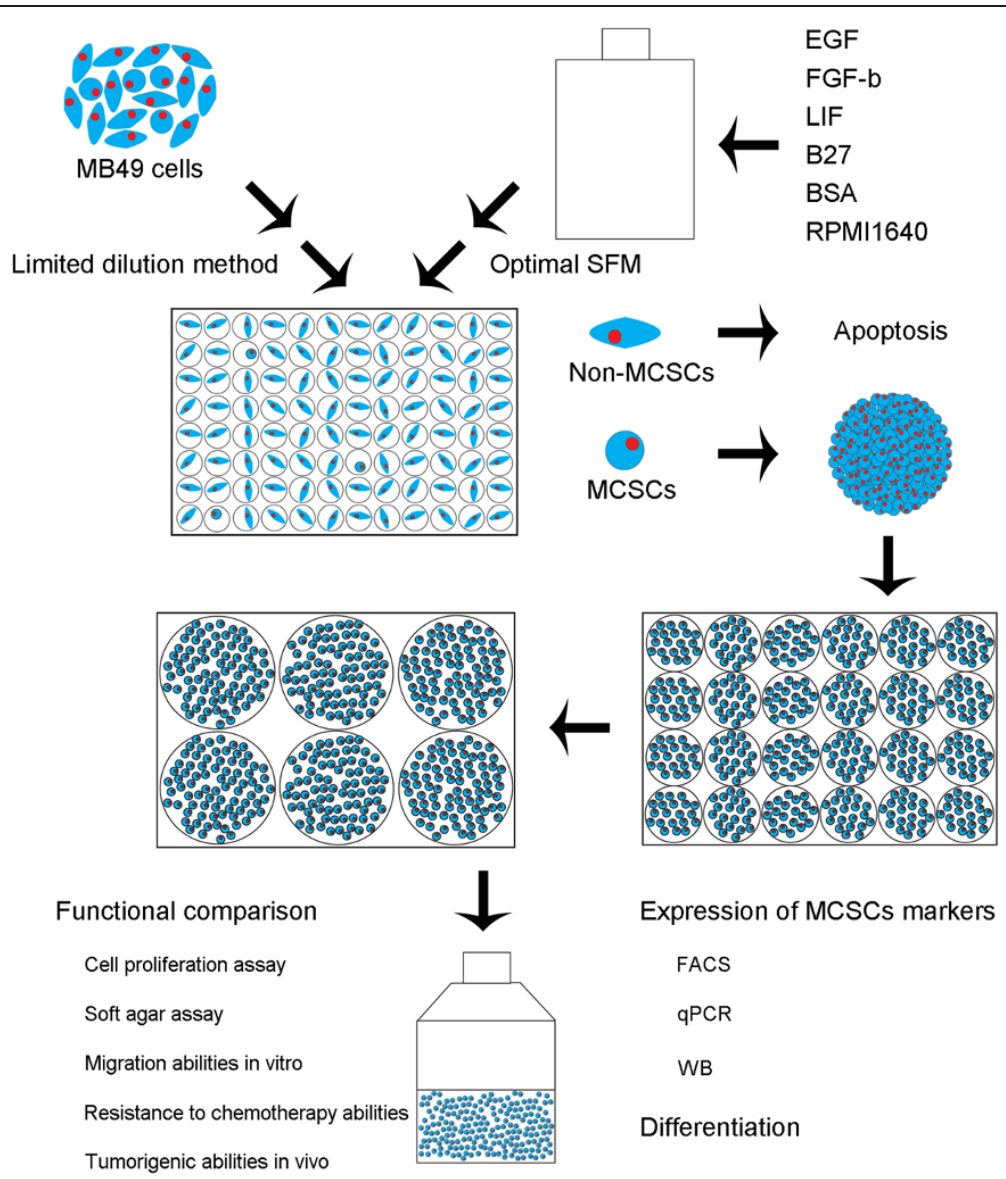

Figure 5 Diagram illustration to the proposed model for isolation of MCSCs by combination of limited dilution method and optimal SFM method.

a combination of limited dilution and SFM methods, which is modified to improve the purity of CSCs.

CD133 and CD44 have been used to identify CSCs from other cancer tissues $[18,19]$. Interestingly, our results showed an elevated $\mathrm{CD} 44^{+} \mathrm{CD} 133^{+}$expression in MCSCs. OCT4 played a significant role in self-renewal [20], and NANOG was identified as a key molecule to maintain self-renewal and to block differentiation [21]. These genes can potentially lead to tumorigenesis and affect some cancer behaviors, such as resistance to therapies or cancer recurrence[6]. They were not only upregulated at the protein level (WB) but also at the mRNA transcript level (qPCR) in MCSCs.

The capability to differentiate was another important feature of CSCs [8]. Furthermore, we applied the techniques to functionally characterize MCSCs populations $[22,23]$. MCSCs had typical CSCs that were capable of self-regeneration with a higher proliferative capacity and greater colony formation potential. MCSCs showed the greater capacity to penetrate wells, which indicated that these cells were the most likely to migrate.

Chemotherapy killed the majority of cells in a tumor, but it did not kill CSCs, which might be the mechanism behind the resistance to chemotherapy [24,25]. MCSCs had a lower susceptibility to mitomycin, cisplatin, paclitaxel and doxorubicin. The ATP-binding cassette $(\mathrm{ABC})$ transporters explained the mechanism that many chemical drugs were pumped out of cells by ABC transporters [26]. MCSCs showed a higher level of ABCG2 expression at the protein level (WB), and the upregulation of ABCG2 was associated with the resistance of MCSCs to anti-cancer drugs. The standard experimental method for the isolation of CSCs was to test the tumorigenicity of cancer cells in immunodeficient mice [27]. MCSCs showed the greatest ability to form tumors in the subcutaneous tissues of immunodeficient mice.

Taken together, this data showed that cultured MCSCs displayed specific CSC properties. In conclusion, MCSCs were isolated successfully with a modified method using a combination of limited dilution and SFM methods. MCSCs contained characteristics resembling CSCs such as in vitro self-renewal, a differentiation potential, chemotherapy resistance and in vivo tumorigenic capacity. MCSCs may provide an ideal model for the development of bladder cancer vaccine research. 


\section{Competing interest}

All authors have no conflict of interest regarding this paper.

\section{Author contributions}

$Y Z, Y D$ and $W T$ conceived and designed the experiments; $Y Z, C L, N L, Y L$ and $\mathrm{CH}$ performed the experiments; $Y Z, W C$ and $F L$ analyzed the data; $Y Z, N L$, WC and FL contributed reagents/materials/analysis tools; YZ, NL and WT wrote the paper; All authors read and approved the final manuscript.

\section{Acknowledgement}

This study was supported by the National Natural Science Foundation of China (No.81272844)

\section{Author details}

'Department of Urology, Nanfang Hospital, Southern Medical University, Guangzhou, Guangdong 510515, P.R. China. 'Department of Gynecology, Zhujiang Hospital, Southern Medical University, Guangzhou, Guangdong 510515, P.R. China. ${ }^{3}$ Department of Pathology, Southern Medical University, Guangzhou, Guangdong 510515, P.R. China.

Received: 8 September 2013 Accepted: 26 October 2013

Published: 4 November 2013

\section{References}

1. Zhang X, Shi X, Li J, Hu Z, Guo F, Huang X, Zhang Z, Sun P, Jing Y, Gao J, Tan W: Novel immunotherapy for metastatic bladder cancer using vaccine of human interleukin-2 surface-modified MB 49 cells. Urology 2011, 78(3):721-722.

2. Zhang X, Shi X, Li J, Hu Z, Zhou D, Gao J, Tan W: A novel therapeutic vaccine of mouse GM-CSF surface modified MB49 cells against metastatic bladder cancer. J Urol 2012, 187(3):1071-1079.

3. Shi X, Zhang X, Li J, Guo F, Hu Z, Jing Y, Bai L, Chen S, Wan P, Wang F, Gao J, Tan W: Sequential administration of GM-CSF and IL-2 surface-modified MB49 cells vaccines against the metastatic bladder cancer. Urol Oncol 2013 31(6):883-893.

4. Ho PL, Kurtova A, Chan KS: Normal and neoplastic urothelial stem cells: getting to the root of the problem. Nat Rev Urol 2012, 9(10):583-594.

5. Li G, Liu C, Yuan J, Xiao X, Tang N, Hao J, Wang H, Bian X, Deng Y, Ding Y: CD133(+) single cell-derived progenies of colorectal cancer cell line SW480 with different invasive and metastatic potential. Clin Exp Metastasis 2010, 27(7):517-527.

6. Li L, Li B, Shao J, Wang X: Chemotherapy sorting can be used to identify cancer stem cell populations. Mol Biol Rep 2012, 39(11):9955-9963.

7. Zhang Y, Wang Z, Yu J, Shi J, Wang C, Fu W, Chen Z, Yang J: Cancer stem-like cells contribute to cisplatin resistance and progression in bladder cancer. Cancer Lett 2012, 322(1):70-77.

8. Bentivegna A, Conconi D, Panzeri E, Sala E, Bovo G, Vigano P, Brunelli S, Bossi M, Tredici G, Strada G, Dalpra L: Biological heterogeneity of putative bladder cancer stem-like cell populations from human bladder transitional cell carcinoma samples. Cancer Sci 2010, 101(2):416-424.

9. Jung $S$, Panchalingam KM, Rosenberg L, Behie LA: Ex vivo expansion of human mesenchymal stem cells in defined serum-free media. Stem Cells Int 2012, 2012:123030.

10. Pan Z, Hooley J, Smith DH, Young P, Roberts PE, Mather JP: Establishment of human ovarian serous carcinomas cell lines in serum free media. Methods 2012, 56(3):432-439.

11. Yao CL, Chu IM, Hsieh TB, Hwang SM: A systematic strategy to optimize ex vivo expansion medium for human hematopoietic stem cells derived from umbilical cord blood mononuclear cells. Exp Hematol 2004, 32(8):720-727.

12. Wang L, Mezencev R, Bowen NJ, Matyunina LV, McDonald JF: Isolation and characterization of stem-like cells from a human ovarian cancer cell line. Mol Cell Biochem 2012, 363(1-2):257-268.

13. Liao WT, Jiang D, Yuan J, Cui YM, Shi XW, Chen CM, Bian XW, Deng YJ, Ding YQ: HOXB7 as a prognostic factor and mediator of colorectal cancer progression. Clin Cancer Res 2011, 17(11):3569-3578.

14. Qiang L, Yang Y, Ma YJ, Chen FH, Zhang LB, Liu W, Qi Q, Lu N, Tao L, Wang XT, You OD, GuO QL: Isolation and characterization of cancer stem like cells in human glioblastoma cell lines. Cancer Lett 2009, 279(1):13-21.
15. Varghese S, Whipple R, Martin SS, Alexander HR: Multipotent cancer stem cells derived from human malignant peritoneal mesothelioma promote tumorigenesis. PLoS One 2012, 7(12):e52825.

16. She JJ, Zhang PG, Wang ZM, Gan WM, Che XM: Identification of side population cells from bladder cancer cells by DyeCycle Violet staining. Cancer Biol Ther 2008, 7(10):1663-1668.

17. Yanamoto S, Kawasaki G, Yamada S, Yoshitomi I, Kawano T, Yonezawa H, Rokutanda S, Naruse T, Umeda M: Isolation and characterization of cancer stem-like side population cells in human oral cancer cells. Oral Oncol 2011, 47(9):855-860.

18. Brescia P, Richichi C, Pelicci G: Current strategies for identification of glioma stem cells: adequate or unsatisfactory? J Oncol 2012, 2012:376894.

19. Han ME, Jeon TY, Hwang SH, Lee YS, Kim HJ, Shim HE, Yoon S, Baek SY, Kim BS, Kang CD, Oh SO: Cancer spheres from gastric cancer patients provide an ideal model system for cancer stem cell research. Cell Mol Life Sci 2011, 68(21):3589-3605

20. Felthaus O, Ettl T, Gosau M, Driemel O, Brockhoff G, Reck A, Zeitler K, Hautmann M, Reichert TE, Schmalz G, Morsczeck C: Cancer stem cell-like cells from a single cell of oral squamous carcinoma cell lines. Biochem Biophys Res Commun 2011, 407(1):28-33.

21. Gong C, Liao H, Guo F, Qin L, Qi J: Implication of expression of Nanog in prostate cancer cells and their stem cells. J Huazhong Univ Sci Technolog Med Sci 2012, 32(2):242-246.

22. Dalerba P, Cho RW, Clarke MF: Cancer stem cells: models and concepts. Annu Rev Med 2007, 58:267-284.

23. Visvader JE, Lindeman GJ: Cancer stem cells in solid tumours: accumulating evidence and unresolved questions. Nat Rev Cancer 2008, 8(10):755-768.

24. Sung JM, Cho HJ, Yi H, Lee CH, Kim HS, Kim DK, Abd EA, Kim JS, Landowski CP, Hediger MA, Shin HC: Characterization of a stem cell population in lung cancer A549 cells. Biochem Biophys Res Commun 2008, 371(1):163-167.

25. Okamoto A, Chikamatsu K, Sakakura K, Hatsushika K, Takahashi G, Masuyama K: Expansion and characterization of cancer stem-like cells in squamous cell carcinoma of the head and neck. Oral Oncol 2009, 45(7):633-639.

26. Scopelliti A, Cammareri P, Catalano V, Saladino V, Todaro M, Stassi G: Therapeutic implications of cancer initiating cells. Expert Opin Biol Ther 2009, 9(8):1005-1016.

27. Lobo NA, Shimono Y, Qian D, Clarke MF: The biology of cancer stem cells. Annu Rev Cell Dev Biol 2007, 23:675-699.

doi:10.1186/1471-2490-13-57

Cite this article as: Zhu et al:: A modified method for isolation of bladder cancer stem cells from a MB49 murine cell line. BMC Urology 2013 13:57.

\section{Submit your next manuscript to BioMed Central and take full advantage of:}

- Convenient online submission

- Thorough peer review

- No space constraints or color figure charges

- Immediate publication on acceptance

- Inclusion in PubMed, CAS, Scopus and Google Scholar

- Research which is freely available for redistribution 